\title{
A case of atypical Takayasu arteritis initially presenting with peripheral artery disease
}

\author{
Hiroshi Kawano, Masaki Hanibuchi, Terumi Yoshijima, Yuko Toyoda, J un Kishi, Toshifumi \\ Tezuka, Yasuhiko Nishioka
}

Department of Respiratory Medicine and Rheumatology, Institute of Health Biosciences, The University of Tokushima Graduate School, Tokushima, Japan

Correspondence: Yasuhiko Nishioka. Address: Department of Respiratory Medicine and Rheumatology, Institute of Health Biosciences, University of Tokushima Gradate School, Tokushima, Japan. E-mail: yasuhiko@tokushima-u.ac.jp

Received: July 9, 2014

DOI : $10.5430 /$ crcp.v2n2p34
Accepted: November 15, 2014 Online Published: December 18, 2014

URL: http://dx.doi.org/10.5430/crcp.v2n2p34

\section{Abstract}

A 28-year-old woman developed Raynaud's phenomenon and sudden left visual loss due to hypertensive retinopathy. One and a half years later, she noticed peripheral coldness and numbness of right foot. Enhanced computed tomography showed remarkable stenosis of left radial and bilateral tibial arteries. Initially, the diagnosis of idiopathic peripheral arterial occlusive disease (PAD) was made. PAD gradually progressed despite the medication with antiplatelet drug and vasodilator, and coronary angiography revealed a left coronary artery aneurysm. Then, she developed the same ischemic symptom of right hand and left visual loss caused by papilledema. Although ${ }^{18} \mathrm{~F}$-fluorodeoxyglucose positron-emission tomography showed no abnormalities, and both HLA-B52 and HLA-B39 were negative, she was diagnosed with atypical Takayasu arteritis (TA) by exclusion of other possible diseases. To the best of our knowledge, this is the first case of TA with coronary aneurysm and PAD. In TA patients, the involvement of medium-sized vascular lesion such as peripheral extremity arteries should be considered.

\section{Key words}

Takayasu arteritis, Raynaud's phenomenon, Papilledema, Peripheral artery disease, Coronary artery aneurysm

\section{Introduction}

Takayasu arteritis (TA) is a chronic granulomatous vasculitis of unknown etiology, with a predilection for the aorta and its major branches. Women are affected in 80 to 90 percent of cases, typically before the age of 40 years ${ }^{[1]}$. In Japan, more than 5,000 cases are registered by the government and the number of patients increases by 200 to 400 every 3 years ${ }^{[2]}$. A positive association with HLA-B52 and HLA-B39 has been demonstrated in several studies, suggesting an immunogenic association ${ }^{[3]}$. Systemic symptoms are common in the early phase of TA, including fatigue, weight loss, and low-grade fever. However, some cases may be asymptomatic until vascular involvement becomes clinically apparent due to dilatation, narrowing, or occlusion of the proximal or distal branches of the aorta. There are no blood tests specific for TA. Acute phase reactants, such as an elevated erythrocyte sedimentation rate (ESR), an increased serum C-reactive protein (CRP) are not always precise or invariably reliable indicators of the disease. Because of the nonspecific nature of its clinical symptoms, TA is often undiagnosed until its later stage. In advanced cases, occlusion of the vessels to the extremities may result in ischemic ulcerations or gangrene. Coronary involvement also may occur and induce angina 
pectoris or myocardial infarction. Here, we report a case of TA who developed claudication due to peripheral arterial occlusive disease (PAD), unilateral papilledema and coronary artery aneurysm. Although the size of coronary aneurysm did not change during treatment with immunosuppressive treatments, PAD progressed gradually.

\section{Case presentation}

A 25-year-old Japanese woman suffered from Raynaud's phenomenon on her left fingers. Two years later, she developed sudden left visual loss, and had a diagnosis and treatment of hypertensive retinopathy. After one and a half years, she noticed peripheral coldness and numbness of right foot, and was referred to cardiovascular department. Enhanced computed tomography (CT) scan showed occlusion of left radial artery and a remarkable stenosis of bilateral tibial arteries. She had no history of smoking. Although she had an acceleration of ESR, there was no evidence of large vessel vasculitis. As a result, cardiologist made the diagnosis of idiopathic PAD. She continued to be treated with antiplatelet drug and vasodilator, but six months later, coronary angiography revealed a left coronary artery aneurysm without any stenotic lesions (see Figure 1).

Figure 1. Angiography showing aneurysm of the left main coronary artery (arrow).

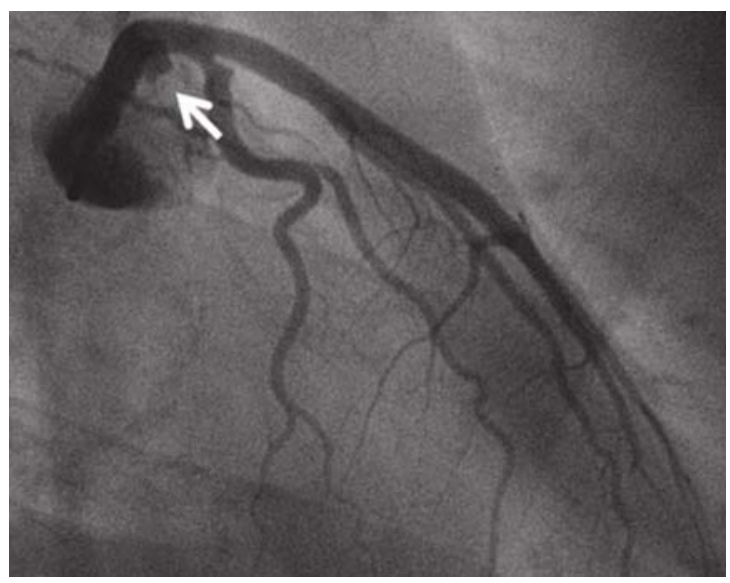

Then, she developed the same coldness with pain on her right hand, and left visual loss worsened. She was suspected to have connective tissue disease, and admitted to our department.

Her body temperature was $36.9^{\circ} \mathrm{C}$, heart rate was $84 / \mathrm{min}$, blood pressure was within normal range with no bilateral difference. Her respirations and oxygen saturation were normal. Physical examination revealed cyanosis on both hands and right foot. In addition, bilateral radial and dorsal arteries were not palpable, and vascular bruit in neck, chest and abdomen were not audible. Her left visual loss turned out to be caused by papilledema (see Figure 2).
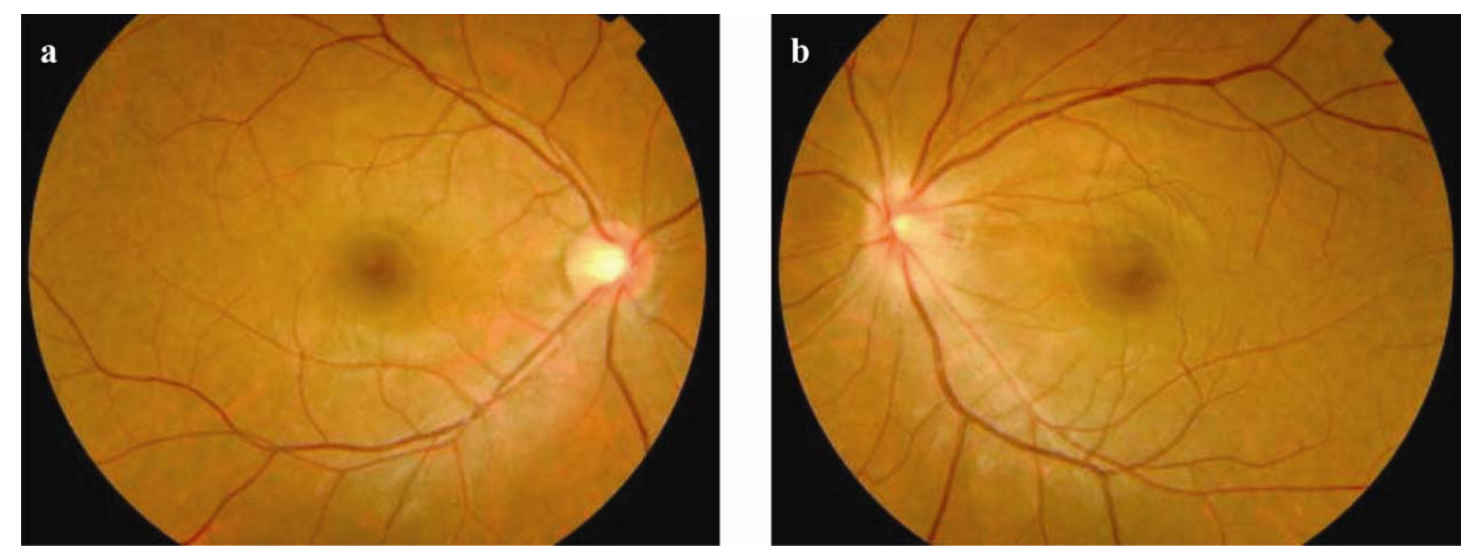

Figure 2. a. Normal right eye fundus photograph. b. Blurred left optic disc showed papilledema. 
A blood test revealed white blood cells $2,400 / \mu 1$, hemoglobin $12.9 \mathrm{~g} / \mathrm{dl}$, and platelets $17.6 \times 10^{4} / \mu 1$. While CRP was within normal range $(0.05 \mathrm{mg} / \mathrm{dl})$, ESR was elevated $(36 \mathrm{~mm} / \mathrm{h})$. Screening for hypercoagulopathy, autoantibodies and typical HLA typing (HLA-B52, B39) were negative (see the table).

Table. Laboratory findings on admission

\begin{tabular}{|c|c|c|c|}
\hline \multicolumn{3}{|l|}{ Blood count } & \multirow{2}{*}{$\begin{array}{l}\text { (Normal Range) } \\
(4000-9000)\end{array}$} \\
\hline White blood cells & 2400 & $/ \mu 1$ & \\
\hline Red blood cells & $397 \times 10^{4}$ & $/ \mu 1$ & $(390-490)$ \\
\hline Hemoglobin & 12.9 & $\mathrm{~g} / \mathrm{dl}$ & $(11.5-14.5)$ \\
\hline Hematocrit & 38.4 & $\%$ & $(34-43)$ \\
\hline Platelets & $17.6 \times 10^{4}$ & $/ \mu 1$ & $(15.0-35.0)$ \\
\hline \multicolumn{4}{|l|}{ Serum chemistry } \\
\hline ТP & 8.1 & $\mathrm{~g} / \mathrm{dl}$ & $(6.5-8.2)$ \\
\hline AST & 16 & $\mathrm{IU} / 1$ & $(10-35)$ \\
\hline ALT & 11 & $\mathrm{IU} / 1$ & $(5-40)$ \\
\hline BUN & 12 & $\mathrm{mg} / \mathrm{dl}$ & $(8-20)$ \\
\hline $\mathrm{Cr}$ & 0.74 & $\mathrm{mg} / \mathrm{dl}$ & $(0.4-0.9)$ \\
\hline \multicolumn{4}{|l|}{ Coagulation tests } \\
\hline PT & 11.7 & $\mathrm{sec}$ & $(10.5-13.4)$ \\
\hline APTT & 35.7 & $\mathrm{sec}$ & $(24.3-35.0)$ \\
\hline D-dimer & 0.8 & $\mu \mathrm{g} / \mathrm{ml}$ & $(<1.0)$ \\
\hline Lupus anticoagulant & 1.21 & & $(<1.3)$ \\
\hline Protein C & 85 & $\%$ & $(62-131)$ \\
\hline Protein S & 50 & $\%$ & $(60-127)$ \\
\hline \multicolumn{4}{|c|}{ Immunological findings } \\
\hline CRP & 0.05 & $\mathrm{mg} / \mathrm{dl}$ & $(<0.3)$ \\
\hline IgG & 2097 & $\mathrm{mg} / \mathrm{dl}$ & $(870-1700)$ \\
\hline $\mathrm{C} 3$ & 93 & $\mathrm{mg} / \mathrm{dl}$ & $(65-135)$ \\
\hline $\mathrm{C} 4$ & 20 & $\mathrm{mg} / \mathrm{dl}$ & $(13-35)$ \\
\hline CH50 & 61 & $\mathrm{U} / \mathrm{ml}$ & $(32-49)$ \\
\hline ANA & 320 & fold & $(<40)$ \\
\hline \multicolumn{4}{|l|}{ Homogenous } \\
\hline Anti-dsDNA Ab & $<10$ & $\mathrm{IU} / \mathrm{ml}$ & $(<12)$ \\
\hline Anti-Sm Ab & - & fold & (negative) \\
\hline Anti- $\beta 2$ GPI & $<0.7$ & $\mathrm{U} / \mathrm{ml}$ & $(<3.5)$ \\
\hline Anti-centromere $\mathrm{Ab}$ & $<5.0$ & $\mathrm{EU}$ & $(<7)$ \\
\hline Anti-Scl-70 Ab & - & fold & (negative) \\
\hline $\mathrm{RF}$ & $<10$ & $\mathrm{IU} / \mathrm{ml}$ & $(<15)$ \\
\hline MMP-3 & 24.2 & $\mathrm{ng} / \mathrm{ml}$ & $(17.3-59.7)$ \\
\hline MPO-ANCA & $<10$ & $\mathrm{EU}$ & $(<20)$ \\
\hline PR3-ANCA & $<10$ & EU & $(<10)$ \\
\hline
\end{tabular}

An enhanced CT showed occlusion of left radial and bilateral anterior tibial arteries, together with severe stenosis of left ulnar and both posterior tibial arteries (see Figure 3a, b).

Typical findings of aorta or its major branches involvement was absent, and ${ }^{18} \mathrm{~F}$-fluorodeoxyglucose positron-emission tomography $\left({ }^{18} \mathrm{~F}\right.$-FDG-PET) did not reveal areas of increased uptake of the tracer. Based on the presence of coronary artery aneurysm, unilateral papilledema and progressive PAD, a diagnosis of TA was made without histological examination. She was treated with high-dose oral prednisolone $(1 \mathrm{mg} / \mathrm{kg} /$ day), but her claudication did not improve (see Figure 4). 

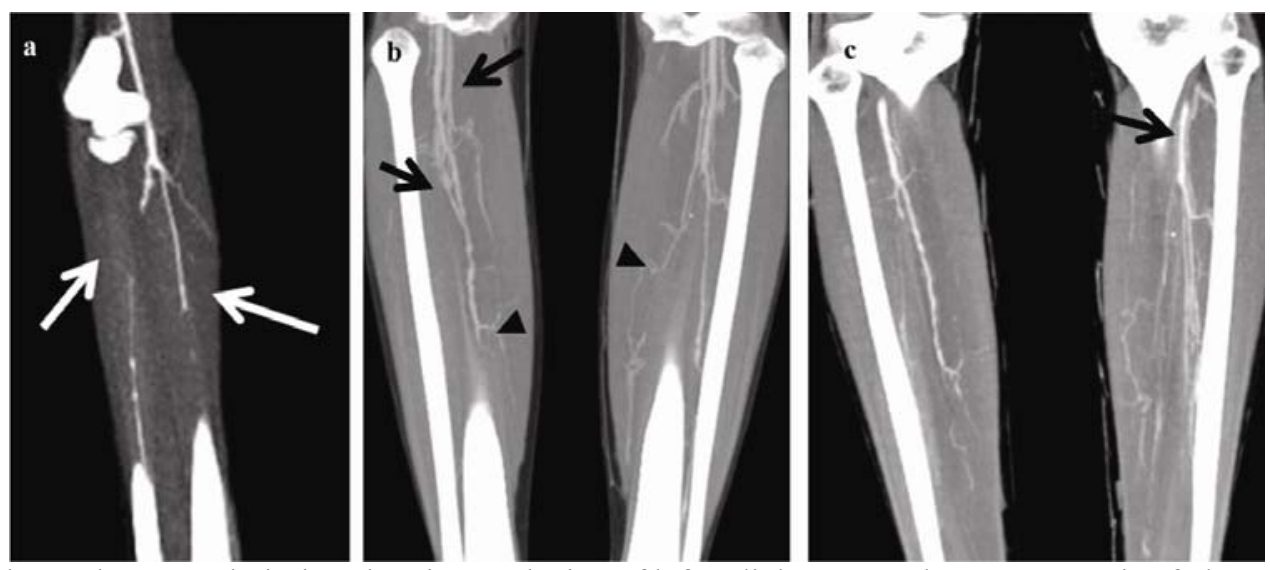

Figure 3. a. Enhanced CT on admission showing occlusion of left radial artery and severe stenosis of ulner artery (arrows). b. Poor visualization of bilateral lower leg arteries; occlusion of right anterior tibial and peroneal arteries (arrows), severe stenosis of bilateral posterior tibial arteries (arrow heads). c. Repeated CT after three months of treatment showed progression of stenosis; left anterior tibial artery was occluded (arrow).
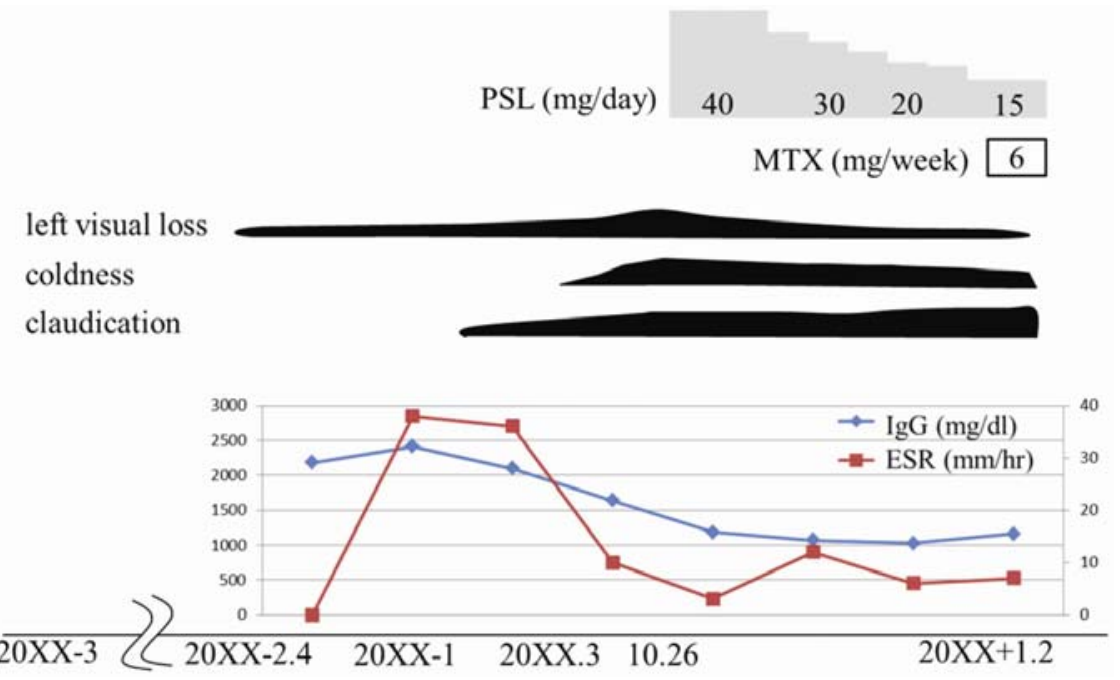

Figure 4. Clinical course. High-dose oral prednisolone (PSL) and oral methotrexate (MTX) were ineffective for ischemic symptoms.
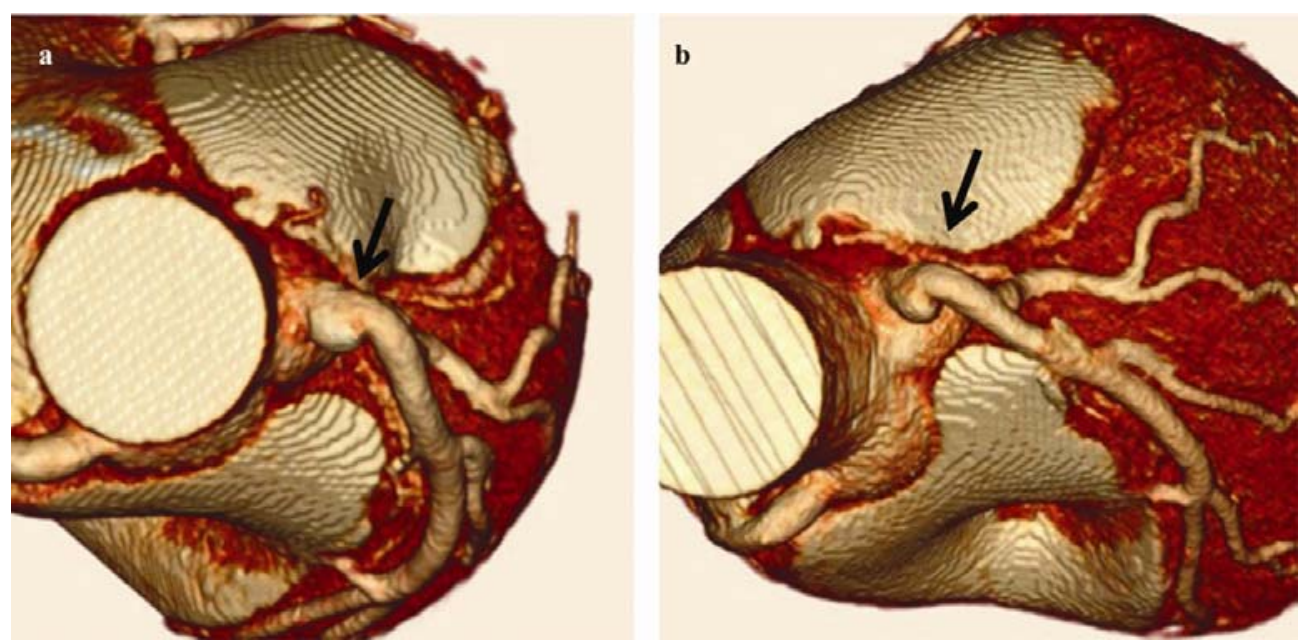

Figure 5. a. CT coronary angiography depicting aneurysm of the left main coronary artery (arrow). b. After addition of MTX coronary aneurysm did not enlarge (arrow). 
Three months later, the progression of extremity artery lesions was demonstrated by CT scan (see Figure $3 b, c)$. An addition of methotrexate (MTX) $6 \mathrm{mg} /$ week was also ineffective for PAD, although the size of coronary aneurysm did not change during treatment with MTX (see Figure 5a, b). Biologics like TNF- $\alpha$ or IL-6 inhibitors were considered as next treatment options. Moreover, surgical treatment should be taken into account, when medical treatments are not successful.

\section{Discussion}

Aneurysm of the left main coronary artery is rare with an incidence of $0.1 \%$ in large angiographic series ${ }^{[4]}$. The majority are atherosclerotic in origin. Other causes include connective tissue disorders, trauma, congenital, mycotic and idiopathic. In the present case, coronary artery aneurysm might be congenital or idiopathic, but complication of progressive PAD and unilateral papilledema suggested the possibility of vasculitis. Despite the lack of histological evidence, we classified the present case into atypical TA based on exclusion of possible differential diseases including other vasculitis; such as Kawasaki disease, Buerger's disease, giant cell arteritis (GCA), polyarteritis nodosa, and ANCA-associated vasculitis. The classification criteria of the American College of Rheumatology include age, symptoms, signs, and angiographic findings related to the involvement of the aorta and its major branches ${ }^{[5]}$. The presence of more than three items suggests a high probability of TA, and indeed the present case satisfied 3 out of 6 classification criteria items.

Coronary arterial involvement is observed in approximately $10 \%$ of TA cases and can be divided into 3 distinct morphologic types: stenosis or occlusion of the coronary ostia, diffuse or focal coronary arteritis, and coronary aneurysm formation ${ }^{[6]}$. Most of the lesions cause luminal narrowing that can lead to occlusion, and coronary aneurysms are extremely rare. Coronary aneurysms often cause stasis of blood flow and result in mural thrombus and myocardial infarction. They can also become enlarged and lead to rupture, cardiac tamponade, and sudden death ${ }^{[6]}$.

In general, claudication of TA is thought to be derived from proximal branches of aorta. However, Beschorner et al. reported atypical TA case with bilateral occlusion of the superficial femoral arteries, in which catheter biopsy showed inflammatory infiltrates consistent with TA ${ }^{[7]}$. In addition, Assie et al. reported a series of 36 patients with upper and/or lower extremity vasculitis related to GCA. Reconstructive study was performed in 10 patients. Histology of the vessels was obtained only in the 2 patients who underwent limb amputation; histologic analyses of vessel tissues showed damage consistent with active $\mathrm{GCA}^{[8]}$. Recently, some reports have suggested that TA and GCA are the same disease, because the histopathologic features are indistinguishable ${ }^{[9]}$. Chapel Hill Consensus Conference 2012 (CHCC2012) participants retained prior guidelines that consider TA to be a disease predominantly of younger individuals and GCA to be a disease predominantly of older individuals ${ }^{[10]}$. These reports justify suggesting that TA as well as GCA patients may exhibit peripheral upper/lower extremity arterial involvement. And, in such cases, peripheral vascular Doppler ultrasound can be a useful modality for the assessment of lesions. Although peripheral smaller extremity artery lesions may not present like a "macaroni sign", which is characteristic circumferential arterial wall thickening of the common carotid arteries, Doppler ultrasound can detect existence of these lesions noninvasively. ${ }^{18}$ F-FDG-PET can be used to image the aorta and great vessels, and theoretically be able to distinguish vessel thickening that is due to active inflammation from that due to scar formation. The utility of ${ }^{18}$ F-FDG-PET in patients with peripheral vascular lesions is unclear. Niccoli Asabella A et al. reported target background ratio compared to standardized uptake value at the carotid plaque significantly correlated with the presence of carotid inflammation ${ }^{[11]}$. This methodology might be applicable to peripheral artery lesions in the present case.

In TA, ocular manifestations are not uncommon ${ }^{[12]}$. Occlusive arteritis of the aortic arch branches results in ischemic ocular lesions, especially retinopathy. Involvement of the renal artery or supra-renal aorta causes hypertensive eye manifestations, including papilledema. Although papilledema is almost universally bilateral, the appearance may be unilateral if there are ischemic, inflammatory, or infiltrative optic nerve lesions. GCA is a common cause of arteritic anterior ischemic optic neuropathy (AION) which may lead to unilateral papilledema. However, TA cases associated with AION ${ }^{[13]}$, central retinal artery occlusion ${ }^{[14]}$, and ocular ischemic syndrome have been described infrequently ${ }^{[15]}$. When 
the present case developed left papilledema, hypertension was well controlled and stenosis of aortic arch branches was absent. We therefore assumed that papilledema might be due to transient AION.

There is no consensus regarding the treatment approach of coronary and extremity artery lesions related to TA. It is unclear whether corticosteroids and other immunosuppressants improve these lesions. In atypical TA case reports that described coronary artery aneurysm complicated with acute myocardial infarction, acute management consisted of thrombolytic therapy or intravenous abciximab ${ }^{[16]}$. In some cases, surgical management of coronary artery disease was required ${ }^{[16]}$. Assie et al. reported that all patients with extremity vasculitis related to GCA were given steroid therapy at a median daily dose of $1 \mathrm{mg} / \mathrm{kg}$ predonisolone initially and immunosuppressive drugs (MTX, azathioprine, or cyclophosphamide) were added in some patients ${ }^{[8]}$. In the present case, we initiated high-dose oral prednisolone $(1 \mathrm{mg} / \mathrm{kg} / \mathrm{day})$ and then added MTX. Although coronary artery aneurysm did not enlarge, the extremity artery lesions gradually progressed. The alternative therapeutic interventions, such as biologics and surgery, might be required in near future.

In conclusion, we reported a case of atypical TA initially presenting with PAD. To the best of our knowledge, this is the first case report of TA with coronary aneurysm and PAD. The possibility of coronary and peripheral extremity artery lesion should be considered in TA patients.

\section{References}

[1] Lupi-Herrera E, Sánchez-Torres G, Marcushamer J, Mispireta J, Horwitz S, Vela JE. Takayasu's arteritis. Clinical study of 107 cases. Am Heart J. 1977; 93(1): 94-103. http://dx.doi.org/10.1016/S0002-8703(77)80178-6

[2] Japanese Circulation Society Joint working Group. Guideline for management of vasculitis syndrome (Japanese Circulation Society 2008). Circ J. 2011; 75(2): 474-503. http://dx.doi.org/10.1253/circj.CJ-88-0007

[3] Kimura A, Kitamura H, Date Y, Numano F. Comprehensive analysis of HLA genes in Takayasu arteritis in Japan. Int J Cardiol. 1996; 54 Suppl: S61-9. http://dx.doi.org/10.1016/S0167-5273(96)88774-2

[4] Topaz O, DiSciascio G, Crowley MJ, Goudreau E, Soffer A, Nath A, et al. Angiographic features of the left main coronary artery aneurysms. Am J Cardiol. 1991; 67(13): 1139-42. http://dx.doi.org/10.1016/0002-9149(91)90881-K

[5] Arend WP, Michel BA, Bloch DA, Hunder GG, Calabrese LH, Edworthy SM, et al. The American College of Rheumatology 1990 criteria for the classification of Takayasu arteritis. Arthritis Rheum. 1990; 33(8): 1129-34. http://dx.doi.org/10.1002/art.1780330811

[6] Suzuki H, Daida H, Tanaka M, Sato H, Kawai S, Sakurai H, et al. Giant aneurysm of the left main coronary artery in Takayasu aortitis. Heart. 1999; 81(2): 214-7. http://dx.doi.org/10.1136/hrt.81.2.214

[7] Beschorner U, Goebel H, Rastan A, Sixt S, Zeller T. Histological diagnosis of atypical Takayasu arteritis using percutaneous transluminal atherectomy. J Endovasc Ther. 2008; 15(2): 241-3. http://dx.doi.org/10.1583/07-2317.1

[8] Assie C, Janvresse A, Plissonnier D, Levesque H, Marie I. Long-term follow-up of upper and lower extremity vasculitis related to giant cell arteritis. Medicine (Baltimore). 2011; 90(1): 40-51. http://dx.doi.org/10.1097/MD.0b013e318206af16

[9] Grayson PC, Maksimowicz-McKinnon K, Clark TM, Tomasson G, Cuthbertson D, Carette S, et al. Vasculitis Clinical Research Consortium. Distribution of arterial lesions in Takayasu's arteritis and giant cell arteritis. Ann Rheum Dis. 2012; 71(8): 1329-34. http://dx.doi.org/10.1136/annrheumdis-2011-200795

[10] Jennette JC, Falk RJ, Bascon PA, Basu N, Cid MC, Ferrario F, et al. 2012 revised International Chapel Hill Consensus Conference nomenclature of vasculitides. Arthritis Rheum. 2013; 65(1): 1-11. http://dx.doi.org/10.1002/art.37715

[11] Niccoli Asabella A, Ciccone MM, Cortese F, Scicchitano P, Gesualdo M, Zito A, et al. Higher reliability of 18F-FDG target background ratio compared to standardized uptake value in vulnerable carotid plaque detection: a pilot study. Ann Nucl Med. 2014; 28(6): 571-9. http://dx.doi.org/10.1007/s12149-014-0850-9

[12] Chun YS, Park SJ, Park IK, Chung H, Lee J. The clinical and ocular manifestations of Takayasu arteritis. Retina. 2001; 21(2): 132-40. http://dx.doi.org/10.1097/00006982-200104000-00006 
[13] Schmidt MH, Fox AJ, Nicolle DA. Bilateral anterior ischemic optic neuropathy as presentation of Takayasu's disease. J Neuroophthalmol. 1997; 17(3): 156-61. http://dx.doi.org/10.1097/00041327-199709000-00002

[14] Kaushik S, Gupta A, Gupta V, Jain S, Lal V. Retinal arterial occlusion in Takayasu's arteritis. Indian J Ophthalmol. 2005; 53(3): 194-6. http://dx.doi.org/10.4103/0301-4738.16680

[15] Koz OG, Astes A, Numan Alp M, Gultan E, Karaaslan Y, Kural G. Bilateral ocular ischemic syndrome as an initial manifestation of Takayasu's arteritis associated with carotid steal syndrome. Rheumatol Int. 2007; 27(3): 299-302. http://dx.doi.org/10.1007/s00296-006-0194-4

[16] Al-Hulaimi N, Al-Saileek A, Ahmed T, Al-Zaibag M, Pai RG, El-Widaa H. Mixed aneurysmal and obstructive coronary artery disease causing acute myocardial infarction in a young woman with Takayasu's arteritis. Can J Cardiol. 2001; 17(5): 602-5. 